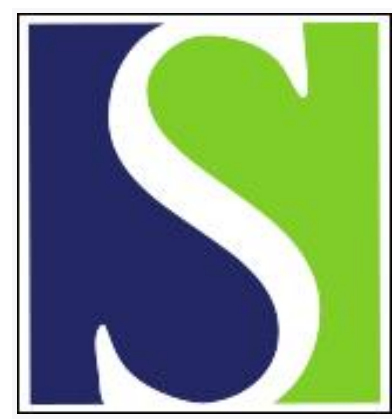

Scand J Work Environ Health 2011;37(6):539-546

https://doi.org/10.5271/sjweh.3175

Published online: 15 Jun 2011, Issue date: Nov 2011

Pregnancy outcomes among female dental personnel - a registry-based retrospective cohort study

by Heggland I, Irgens A, Tollånes M, Romundstad P, Syversen T, Svendsen K, Melø I, Hilt B

Affiliation: Kavli Institute for Systems Neuroscience and Centre for the Biology of Memory, Medical-Technical Research Centre, NO-7491 Trondheim, Norway. ingrid.heggland@ntnu.no

Refers to the following texts of the Journal: $2010 ; 36(3): 231-241$ 1999;25(3):285-290

The following article refers to this text: 2012;38(6):546-552

Key terms: birth defect; cohort study; congenital malformation; dental personnel; dental work; dentist; female dental personnel; mercury; metallic mercury; Norway; Pregnancy outcome

This article in PubMed: www.ncbi.nlm.nih.gov/pubmed/21678018 


\title{
Pregnancy outcomes among female dental personnel - a registry-based retrospective cohort study
}

\author{
by Ingrid Heggland, MSc, ${ }^{1}$ Ågot Irgens, MSc, ${ }^{2}$ Mette Tollånes, PhD, 3,4 Pål Romundstad, PhD, ${ }^{5}$ \\ Tore Syversen, PhD, ${ }^{6}$ Kristin Svendsen, PhD, ${ }^{7}$ Inger Melø, Cand Odont, ${ }^{8}$ Bjørn Hilt, MD ${ }^{1,5}$
}

\begin{abstract}
Heggland I, Irgens Ål, Tollånes M, Romundstad P, Syversen T, Svendsen K, Melø I, Hilt B. Pregnancy outcomes among female dental personnel - a registry-based retrospective cohort study. Scand J Work Environ Health. 2011;37(6):539-546. doi:10.5271/sjweh.3175
\end{abstract}

Objectives The aim of this study was to investigate whether women who have worked as dental personnel in Norway, a group with possible previous exposure to mercury vapor, have had an excess risk of having children with congenital malformations or other adverse pregnancy outcomes compared to the general population.

Methods A cohort of female dental personnel was identified from the archives of the public dental healthcare and the national trade unions in Norway. Data on births and pregnancy outcomes during 1967-2006 were obtained from the Medical Birth Registry of Norway (MBRN). The final cohort of dental personnel consisted of 4482 dental assistants and 1011 dentists. All other women registered in the MBRN were assigned to the control group, in total 1124758 . Excess risks of several adverse pregnancy outcomes for dental personnel compared to the general population were estimated. Analyses were conducted for the whole time period as well as stratified by 10 -year periods.

Results Female dental personnel had no observed increased occurrence of congenital malformations (including malformations of the central nervous system, dysplasia of the hip, clubfoot, malformations of the heart and great vessels), low birth weight, preterm birth, small for gestational age, changed gender ratio, multiple birth, stillbirth, or prenatal death.

Conclusion On a group level, we did not observe any excess risks of congenital malformations or other adverse pregnancy outcomes among female dental personnel in Norway during 1967-2006 compared to the general population.

Key terms birth defect; congenital malformation; dental work; dentist; mercury; metallic mercury; Norway.

Metallic mercury vapor at high doses has well-known neurotoxic effects with symptoms including tremors, fatigue, memory impairment, depression as well as changes in behavior and personality (1). Amalgamcontaining metallic mercury has been used for teeth restoration for several decades, entailing varying degrees of mercury exposure among dental personnel. Whether such occupational exposure has caused deleterious health effects has repeatedly been subject to public debate in the Scandinavian countries, including Nor- way. Some previous studies have shown that dental personnel have had an increased prevalence of cognitive and neuropsychological symptoms (2-5). In 2005, the Norwegian Ministry of Labor and Social Inclusion initiated a study to investigate cognitive symptoms among Norwegian dental personnel. This study found that dental assistants in Norway had a slight increase in the occurrence of cognitive symptoms (6).

In addition to cognitive symptoms, the issue of possible reproductive effects of occupational exposure to

1 Department of Occupational Medicine, St Olav's University Hospital, Trondheim, Norway.

2 Department of Occupational Medicine, Haukeland University Hospital, Bergen, Norway.

3 Laboratory of Clinical Biochemistry, Haukeland University Hospital, Bergen, Norway.

4 Medical birth registry of Norway, University of Bergen and Institute of Public Health, Norway.

5 Department of Public Health and General Practice, Faculty of Medicine, Norwegian University of Science and Technology, Trondheim, Norway.

6 Department of Neuroscience, Faculty of Medicine, Norwegian University of Science and Technology, Trondheim, Norway.

7 Department of Industrial Economics and Technology Management, Norwegian University of Science and Technology, Trondheim, Norway.

8 County Public Dental Services, County of Sør-Trøndelag, Trondheim, Norway.

Correspondence to: Ingrid Heggland, Kavli Institute for Systems Neuroscience and Centre for the Biology of Memory, Medical-Technical Research Centre, NO-7491 Trondheim, Norway. [E-mail: ingrid.heggland@ntnu.no]. 
metallic mercury has been raised. The literature on occupational mercury exposure and pregnancy outcomes is sparse and contains somewhat inconsistent results. Some studies have found an increased rate of miscarriages among women with occupational mercury exposure (7-8), but most studies have found neither such an association (9-15) nor any excess risk of prenatal mortality (11-13). An increased occurrence of congenital malformations in association with mercury exposure has been reported by several researchers $(7,11-12)$ while others have not found any such associations $(8-9,13,16)$.

In 2008, the Norwegian Ministry of Labor and Social Inclusion initiated a follow-up study regarding pregnancy outcomes among dental personnel previously exposed to metallic mercury. In Norway, the degree of exposure to mercury among dental personnel has varied considerably over the last 50 years (17-18). Until the 1980s, a special form of copper amalgam (consisting of 70\% mercury and $30 \%$ copper) was commonly used for restoring deciduous teeth. Solid tablets of copper amalgam were heated to above melting point of the alloy, leading to a high concentration of mercury vapor in the air. In 1973, the levels of mercury vapor were measured in 15 dental clinics, and the reported mean level was $0.043 \mathrm{mg} / \mathrm{m}^{3}$ with measurements ranging from $0.00-0.40 \mathrm{mg} / \mathrm{m}^{3}(19)$. Dental silver amalgam has been widely used, with different preparation methods causing variable levels of exposure throughout the years (17). Due to the introduction of prefabricated capsules, the exposure has been negligible since about 1990 (18) and, from 2008 onwards, the use of dental amalgam has been prohibited in Norway. Correspondingly, measurements of mercury levels in urine among Norwegian dental personnel as part of a voluntary monitoring showed a reduction of about $90 \%$ from the 1960 s to the 1990 s. In the 1960 s, $62 \%$ of the samples were over the biological limit value of $200 \mathrm{nmol} / \mathrm{l}$ compared to none in the 1990s (18). Thus, the main concern has been that women working in dental healthcare prior to 1990 have been exposed to levels of mercury that may have caused reproductive toxicity.

The aim of this study was to investigate whether female dental personnel in Norway, with previous potential exposure to mercury vapor, have had an increased risk of having children with congenital malformations or other adverse pregnancy outcomes on a group level.

\section{Methods}

From dental authorities and public archives, we obtained lists of current and previous employees in the public dental healthcare system from all 19 counties in Norway except one, Rogaland. Employees registered from the establishment of the archives (all prior to 1967) until the time of data collection (2007/2008) were included and all relevant data from the time of employment and onwards were collected. For 14 of the counties, the lists also included information provided by dentists in private practice. In addition, the three largest national trade unions of dental assistants and dentists provided information about members who had been addressed and had agreed to participate in the study. Approximately $44 \%$ (1912) of the trade union members agreed to participate. After collection, the lists were checked and duplications removed. For many of the dental personnel, data were obtained from several sources and were in general consistent (eg, one person ended work in one county the same year as she started work in another county). The data collected on the female dental personnel included name, address, national identification number, occupation, place of work, time period employed or member of the trade union, and graduation year for dentists. The final identified cohort of dental personnel consisted of 7475 female dental assistants and dentists.

The Medical Birth Registry of Norway (MBRN) was established in 1967 and is based on the compulsory notification of all births in Norway after 16 weeks of gestation and after 12 weeks since 2001 (20). The registry includes demographic information about the child and his/her parents, data on complications and interventions during pregnancy and delivery, maternal health before and during pregnancy and the condition of the newborn. From the MBRN, we obtained data on the year of delivery, congenital malformations, neonatal diagnoses, prenatal death, birth weight, gestational age, gender, plurality, maternal age, and parity. Data on the educational level of the mothers was obtained from Statistics Norway.

Record linkage was performed between data from the cohort of dental personnel and data from the MBRN and Statistics Norway, enabled by each mother's unique national identification number. Infants delivered to female dental personnel during 1967-2006 were defined as the exposed group and deliveries to all other females were defined as the unexposed group (control group). The final study population consisted of 1130251 mothers, of whom 5493 were dental personnel. The number of female dental personnel was somewhat lower after alignment with the MBRN because some women had no children or had given birth prior to the establishment of the MBRN in 1967.

Owing to differences in working conditions, the cohort of dental personnel was categorized into two occupational groups: dental assistants and dentists. The data on the time periods of employment were incomplete or missing for a considerable number of the dental personnel. Therefore, by use of the available data on periods of time employed, the dental personnel known to be 
in employment before each delivery were also identified. The data did not include information on maternity leave or other longer leaves, only on termination of employment. Data from trade unions did not include dates of employment, and therefore the women identified solely from trade unions were not included in the group "dental personnel in employment".

The pregnancy outcomes studied were chosen based on the available literature regarding occupational exposure to mercury and reproduction and the availability of data. The following categories of congenital malformations were studied: all congenital malformations registered in the MBRN, major congenital malformations (as defined by the MBRN), malformations of the central nervous system (anencephaly, spina bifida, encephalocele, and hydrocephalus), dysplasia of the hip, clubfoot, and malformations of the heart and great vessels. Other adverse pregnancy outcomes investigated included: low birth weight $(<2500$ grams), preterm delivery $(<37$ weeks gestational age), small for gestational age [SGA, weight below the $10^{\text {th }}$ percentile for actual gestational age in Norwegian newborns (21)], gender distribution (higher proportion of boys), multiple births, stillbirth (death prior to or during delivery) and prenatal death (stillbirth or death during the first month of life).

\section{Statistical analysis}

The excess risks of adverse pregnancy outcomes for dental personnel compared to the control group were estimated using negative binomial regression models with log link [STATA, version 10 (StataCorp, College Station, TX, USA)]. Poisson regression was used when the standard method could not be performed due to colinearity. When the $95 \%$ confidence interval $(95 \% \mathrm{CI})$ did not include one, the test was considered statistically significant. We adjusted for the following potential confounders as categorical variables: parity $(1,2, \geq 3)$, year of delivery $(1967-1976,1977-1986$, 1987-1996, 1997-2006), maternal age $(<25,25$ to 34 , $\geq 35$ ) and maternal education level [primary/unknown
(0-9 years), upper secondary ( $10-12$ years), university/ university college ( $\geq 13$ years)]. Relative risks (RR) with $95 \%$ CI were estimated with births clustered by mother (using the cluster option in STATA), since births by the same mother are not independent events. For the most frequent congenital malformations (all congenital malformations and major congenital malformations) and the other adverse pregnancy outcomes, we estimated the time trend and tested for interaction between time (year of delivery) and occupation, and in addition performed analyses stratified by 10 -year periods (1967-1976, 1977-1986, 1987-1996, and 1997-2006). This was done to investigate whether the risk of adverse outcomes was higher in time periods with assumed high exposure to mercury. Analyses were performed using all dental personnel, as well as sub-analyses using only dental personnel with known employment prior to delivery.

\section{Ethical considerations}

The Regional Committee for Medical and Health Research Ethics in Central Norway evaluated and approved this study.

\section{Results}

Demographic information on the female dentists, dental assistants and the control group is shown in table 1. On average, the women had two children each. Dentists were older than the other groups at the time of their first delivery. The dental assistants had a lower educational level than the control group. Six percent of the dentists were not registered with higher education, possibly owing to incomplete registration of education completed abroad. A formal education for dental assistants was introduced in Norway in the sixties, but many still worked after that based on their occupational experience, but without formal upper-secondary education.

Table 1. Demographic information of the control group and the dental personnel. [SD=standard deviation.]

\begin{tabular}{|c|c|c|c|c|c|c|c|c|c|c|c|c|}
\hline & \multicolumn{4}{|c|}{ Control group } & \multicolumn{4}{|c|}{ Dental assistants } & \multicolumn{4}{|c|}{ Dentists } \\
\hline & $\mathrm{N}$ & Mean & SD & $\%$ & $\mathrm{~N}$ & Mean & SD & $\%$ & $\mathrm{~N}$ & Mean & SD & $\%$ \\
\hline Women & 1124758 & & & & 4482 & & & & 1011 & & & \\
\hline Maternal age at first delivery & & 26.0 & 5.2 & & & 25.1 & 4.5 & & & 29.3 & 3.8 & \\
\hline Number of children per woman & & 2.07 & & & & 2.09 & & & & 2.05 & & \\
\hline Highest registered education & & & & & & & & & & & & \\
\hline Primary and lower secondary/unknown & & & & 27.6 & & & & 24.4 & & & & $4.8^{\mathrm{a}}$ \\
\hline Upper secondary & & & & 43.1 & & & & 64.2 & & & & $1.2^{\mathrm{a}}$ \\
\hline University/university college & & & & 29.3 & & & & 11.4 & & & & 94.0 \\
\hline
\end{tabular}

a The registration of education completed outside Norway is incomplete. 
The occurrence of congenital malformations is shown in table 2. Crude and adjusted analyses are shown for all dental personnel as well as for the sub-cohort of dental personnel with known employment before each birth. When adjusting for potential confounders there were no statistically significant differences in the occurrence of congenital malformations between the groups, except for a reduced risk of children with clubfoot in the group of all dental assistants.

Analyses stratified by 10 -year periods for all congenital malformations are shown in table 3 . There were no significant differences in the risk of adverse outcomes between the groups in any of the time periods. No excess risk was found for any of the time periods in the other malformation categories in the stratified analyses (data not shown).

In addition, in the time trend analysis, a statistically significant increase in the number of registered congenital malformations (all and major) over time was observed $(\mathrm{P}<0.001)$, which did not differ between occupational groups. This increase was probably attributable to revisions of the birth notification form and an improved registration and diagnosis of congenital malformations.
Table 4 shows the occurrence of other adverse pregnancy outcomes in the groups of dental personnel and the control group. No statistically significant differences between groups of dental personnel and the control group were found.

The occurrence of the outcomes low birth weight, preterm birth and multiple births increased over time while a decrease was observed for the outcomes SGA, stillbirth and prenatal death $(\mathrm{P}<0.001$ for all). There was no change in the proportion of male births during the study period.

For the outcomes preterm birth and multiple births, the occupational groups had diverging trends: dental assistants had an increasing risk over time compared to the control group, while the dentists had a decreasing risk. However, in the analyses stratified by 10 -year periods, the risks of these outcomes for dental personnel were not significantly different from the control group in any of the time periods (data not shown). Likewise, the offspring of dental personnel did not have excess risks of low birth weight, SGA, being disproportionately of male gender, stillbirth, and prenatal death in any of the time periods (data not shown). However, occasional

Table 2. Congenital malformations in the offspring of dental personnel and the rest of the population (control group) in Norway, 1967 to 2006. [RR=relative risk; $95 \% \mathrm{Cl}=95 \%$ confidence interval; $\mathrm{Adj}=$ adjusted; ref=reference; $\mathrm{CNS}=$ central nervous system]

\begin{tabular}{|c|c|c|c|c|c|c|c|c|c|c|c|c|}
\hline \multirow{2}{*}{$\begin{array}{l}\text { Outcome and } \\
\text { occupation }\end{array}$} & \multicolumn{6}{|c|}{ All } & \multicolumn{6}{|c|}{ Dental personnel in employment ${ }^{\text {a }}$} \\
\hline & $\mathrm{N}$ & per 1000 & $\mathrm{RR}$ & $95 \% \mathrm{Cl}$ & Adj RR ${ }^{b}$ & $95 \% \mathrm{Cl}$ & $\mathrm{N}$ & per 1000 & $\mathrm{RR}$ & $95 \% \mathrm{Cl}$ & Adj RR ${ }^{b}$ & $95 \% \mathrm{Cl}$ \\
\hline \multicolumn{13}{|l|}{ All malformations } \\
\hline Control group & 75163 & 32.4 & 1.00 & ref & 1.00 & ref & 75163 & 32.4 & 1.00 & ref & 1.00 & ref \\
\hline Dental assistants & 258 & 27.5 & 0.85 & $0.75-0.96$ & 0.90 & $0.76-1.08$ & 114 & 30.5 & 0.94 & $0.78-1.14$ & 0.95 & $0.74-1.23$ \\
\hline Dentists & 79 & 38.1 & 1.19 & $0.95-1.49$ & 0.89 & $0.62-1.28$ & 56 & 35.6 & 1.10 & $0.84-1.45$ & 0.86 & $0.57-1.28$ \\
\hline \multicolumn{13}{|l|}{ Major malformations } \\
\hline Control group & 48954 & 21.1 & 1.00 & ref & 1.00 & ref & 48954 & 21.1 & 1.00 & ref & 1.00 & ref \\
\hline Dental assistants & 172 & 18.4 & 0.87 & $0.74-1.01$ & 0.88 & $0.71-1.09$ & 75 & 20.0 & 0.95 & $0.75-1.21$ & 0.92 & $0.67-1.26$ \\
\hline Dentists & 48 & 23.2 & 1.10 & $0.83-1.47$ & 0.84 & $0.54-1.31$ & 35 & 22.2 & 1.06 & $0.75-1.49$ & 0.79 & $0.48-1.30$ \\
\hline \multicolumn{13}{|c|}{ Malformations of the CNS } \\
\hline Control group & 3481 & 1.5 & 1.00 & ref & 1.00 & ref & 3481 & 1.5 & 1.00 & ref & 1.00 & ref \\
\hline Dental assistants & 12 & 1.3 & 0.85 & $0.46-1.58$ & 0.87 & $0.47-1.60$ & 6 & 1.6 & 1.07 & $0.43-2.71$ & $1.10 \mathrm{c}$ & $0.44-2.77$ \\
\hline Dentists & 1 & 0.5 & 0.32 & $0.05-2.29$ & . & . & 1 & 0.6 & 0.42 & $0.06-3.01$ & . & . \\
\hline \multicolumn{13}{|l|}{ Dysplasia of the hip } \\
\hline Control group & 3780 & 1.6 & 1.00 & ref & 1.00 & ref & 3780 & 1.6 & 1.00 & ref & 1.00 & ref \\
\hline Dental assistants & 6 & 0.6 & 0.39 & $0.18-0.88$ & $0.47^{d}$ & $0.21-1.05 d$ & 2 & 0.5 & 0.33 & $0.08-1.32$ & $0.34 \mathrm{~d}$ & $0.09-1.38$ \\
\hline Dentists & 6 & 2.9 & 1.78 & $0.80-3.97$ & $1.02^{\mathrm{d}}$ & $0.46-2.27 \mathrm{~d}$ & 5 & 3.2 & 1.96 & $0.81-4.71$ & $1.08 \mathrm{~d}$ & $0.45-2.69$ \\
\hline \multicolumn{13}{|l|}{ Clubfoot } \\
\hline Control group & 4132 & 1.8 & 1.00 & ref & 1.00 & ref & 4132 & 1.8 & 1.00 & ref & 1.00 & ref \\
\hline Dental assistants & 11 & 1.2 & 0.66 & $0.36-1.19$ & 0.24 & $0.06-0.94$ & 4 & 1.1 & 0.60 & $0.23-1.61$ & 0.27 & $0.04-1.92$ \\
\hline Dentists & 2 & 1.0 & 0.54 & $0.14-2.17$ & . & . & 2 & 1.3 & 0.71 & $0.18-2.86$ & . & $\cdots$ \\
\hline \multicolumn{13}{|c|}{ Malformations of the heart and great vessels } \\
\hline Control group & 9971 & 4.3 & 1.00 & ref & 1.00 & ref & 9971 & 4.3 & 1.00 & ref & 1.00 & ref \\
\hline Dental assistants & 34 & 3.6 & 0.84 & $0.60-1.19$ & 1.24 & $0.82-1.89$ & 14 & 3.7 & 0.87 & $0.52-1.48$ & 0.96 & $0.48-1.93$ \\
\hline Dentists & 11 & 5.3 & 1.24 & $0.69-2.24$ & 0.73 & $0.27-1.96$ & 9 & 5.8 & 1.33 & $0.69-2.57$ & 0.86 & $0.32-2.30$ \\
\hline
\end{tabular}

a Known to have been employed as dental personnel prior to delivery.

${ }^{b}$ Adjusted for maternal age, educational level, parity and year of birth. Births clustered by mother.

c Poisson regression.

d Poisson regression without adjustment for year of birth. 
Table 3. All congenital malformations in the offspring of dental personnel and the rest of the population (control group) in Norway, stratified by time periods. [RR=relative risk; Adj=adjusted; $95 \% \mathrm{Cl}=95 \%$ confidence interval; ref=reference]

\begin{tabular}{|c|c|c|c|c|c|c|c|c|c|c|c|c|}
\hline \multirow{2}{*}{$\begin{array}{l}\text { Time period and } \\
\text { occupations }\end{array}$} & \multicolumn{6}{|c|}{ All } & \multicolumn{6}{|c|}{ Dental personnel in employment a } \\
\hline & N & per 1000 & $\mathrm{RR}$ & $95 \% \mathrm{Cl}$ & Adj $R^{b}$ & $95 \% \mathrm{Cl}$ & N & per 1000 & $\mathrm{RR}$ & $95 \% \mathrm{Cl}$ & Adj $R^{b}$ & $95 \% \mathrm{Cl}$ \\
\hline \multicolumn{13}{|l|}{ 1967-1976 } \\
\hline Control group & 13598 & 21.5 & 1.00 & ref & 1.00 & ref & 13598 & 21.5 & 1.00 & ref & 1.00 & ref \\
\hline Dental assistants & 65 & 21.5 & 1.00 & $0.78-1.28$ & 0.88 & $0.56-1.39$ & 27 & 26.8 & 1.25 & $0.85-1.84$ & 1.32 & $0.70-2.47$ \\
\hline Dentists & 28 & 17.5 & 0.81 & $0.40-1.63$ & 0.79 & $0.25-2.47$ & 5 & 16.7 & 0.77 & $0.32-1.87$ & 1.07 & $0.34-3.37$ \\
\hline \multicolumn{13}{|l|}{ 1977-1986 } \\
\hline Control group & 15158 & 29.6 & 1.00 & ref & 1.00 & ref & 15158 & 29.6 & 1.00 & ref & 1.00 & ref \\
\hline Dental assistants & 70 & 24.6 & 0.83 & $0.65-1.05$ & 0.88 & $0.64-1.22$ & 28 & 22.1 & 0.74 & $0.51-1.08$ & 0.71 & $0.42-1.20$ \\
\hline Dentists & 13 & 29.6 & 1.00 & $0.58-1.73$ & 0.84 & $0.37-1.90$ & 11 & 31.2 & 1.06 & $0.58-1.92$ & 0.80 & $0.33-1.93$ \\
\hline \multicolumn{13}{|l|}{ 1987-1996 } \\
\hline Control group & 19787 & 33.2 & 1.00 & ref & 1.00 & ref & 19787 & 33.2 & 1.00 & ref & 1.00 & ref \\
\hline Dental assistants & 74 & 31.9 & 0.96 & $0.76-1.21$ & 0.89 & $0.65-1.23$ & 35 & 37.3 & 1.13 & $0.80-1.58$ & 1.06 & $0.69-1.64$ \\
\hline Dentists & 20 & 37.0 & 1.12 & $0.72-1.75$ & 0.72 & $0.34-1.52$ & 12 & 28.4 & 0.85 & $0.48-1.51$ & 0.73 & $0.32-1.64$ \\
\hline \multicolumn{13}{|l|}{ 1997-2006 } \\
\hline Control group & 26620 & 45.7 & 1.00 & ref & 1.00 & ref & 26620 & 45.7 & 1.00 & ref & 1.00 & ref \\
\hline Dental assistants & 49 & 41.7 & 0.91 & $0.68-1.21$ & 0.96 & $0.67-1.38$ & 24 & 45.5 & 1.00 & $0.66-1.50$ & 0.95 & $0.57-1.59$ \\
\hline Dentists & 38 & 59.9 & 1.33 & $0.96-1.85$ & 1.06 & $0.64-1.75$ & 28 & 56.2 & 1.25 & $0.85-1.82$ & 0.92 & $0.52-1.64$ \\
\hline
\end{tabular}

a Known to have been employed as dental personnel prior to delivery.

${ }^{\mathrm{b}}$ Adjusted for maternal age, educational level and parity.

significantly lower risks of some of the outcomes were observed for dental personnel in some of the stratified analyses. For instance where dental assistants (all) had a reduced risk of SGA in the time period 1967-1976 (adjusted RR 0.78, 95\% CI 0.63-0.95) and dental assistants (in employment) had a reduced risk of low birth weight in the time period 1997-2006 (adjusted RR 0.46, $95 \%$ CI $0.23-0.90$ ). However, since the level of significance was not adjusted for multiple testing, these results must be interpreted with care.

We also performed analyses with the dental personnel stratified into groups based on the number of years in employment prior to delivery, which did not influence the results.

\section{Discussion}

In the present study, we did not observe any excess risks of congenital malformations or other adverse pregnancy outcomes for female dental personnel on a group level in Norway during 1967-2006.

The population-based cohort design of this study represents a strength due to the considerable number of deliveries ( $>11000$ among female dental personnel and 2328000 in the control group). As the majority of the cohort of dental personnel was identified from public archives and registries, the risk of selection bias is considered to be low. The women identified from the trade unions, however, were included after agreeing to participate. This might have caused some selection bias, as there has been considerable media attention in Norway over the past few years regarding exposure to mercury and its possible adverse health effects in dental personnel. It is not unlikely that dental personnel who have had health problems or experienced adverse pregnancy outcomes could have been more willing to participate. This could potentially have caused stronger estimates of excess risks in dental personnel. However, we did not observe any such excess risk. In addition, only $10 \%$ of the cohort of dental personnel was identified from the trade unions.

Working as dental personnel in the period before delivery was used as an indicator of occupational exposure, but data on time periods of employment were missing or incomplete for many of the dental personnel (table 2). We cannot rule out that the missing data could have affected the findings. However, analyses performed using the sub-cohort with known employment prior to delivery provided similar results as when using the whole cohort. A dose-response relationship could not be demonstrated either, as stratification based on the number of years of employment prior to delivery did not influence the results.

As the outcomes are registry based, any information bias is likely to be negligible. A certain misclassification of dental personnel as controls was probably present as not all women who had worked as dental personnel were identified as such. However, this is not likely to be related to any of the outcomes and would therefore represent a non-differential misclassification. Likewise, all data on outcomes and potential confounders were collected from the public registries MBRN and Statistics Norway. Even if earlier studies have indicated that the registration of congenital malformations in MBRN may 
Table 4. Adverse pregnancy outcomes among dental personnel and the rest of the population (control group) in Norway, 1967-2006. [RR=relative risk; Adj=adjusted; $95 \% \mathrm{Cl}=95 \%$ confidence interval; ref=reference; SGA=small for gestational age.]

\begin{tabular}{|c|c|c|c|c|c|c|c|c|c|c|c|c|}
\hline \multirow{2}{*}{$\begin{array}{l}\text { Outcome and } \\
\text { occupation }\end{array}$} & \multicolumn{6}{|c|}{ All } & \multicolumn{6}{|c|}{ Dental personnel in employment a } \\
\hline & N & per 100 & RR & $95 \% \mathrm{Cl}$ & Adj $R^{b}$ & $95 \% \mathrm{Cl}$ & N & per 100 & $\mathrm{RR}$ & $95 \% \mathrm{Cl}$ & Adj $R^{b}$ & $95 \% \mathrm{Cl}$ \\
\hline \multicolumn{13}{|l|}{ Low birth weight } \\
\hline Control group & 120975 & 5.2 & 1.00 & ref & 1.00 & ref & 120975 & 5.2 & 1.00 & ref & 1.00 & ref \\
\hline Dental assistants & 484 & 5.2 & 0.99 & $0.89-1.10$ & 0.96 & $0.82-1.12$ & 217 & 5.8 & 1.12 & $0.96-1.32$ & 0.98 & $0.77-1.24$ \\
\hline Dentists & 89 & 4.3 & 0.82 & $0.64-1.04$ & 0.92 & $0.64-1.30$ & 64 & 4.1 & 0.77 & $0.58-1.03$ & 0.90 & $0.61-1.33$ \\
\hline \multicolumn{13}{|l|}{ Preterm birth } \\
\hline Control group & 148474 & 6.8 & 1.00 & ref & 1.00 & ref & 148474 & 6.8 & 1.00 & ref & 1.00 & ref \\
\hline Dental assistants & 555 & 6.2 & 0.92 & $0.83-1.01$ & 0.89 & $0.77-1.03$ & 239 & 6.7 & 0.99 & $0.85-1.15$ & 0.89 & $0.72-1.09$ \\
\hline Dentists & 91 & 4.6 & 0.66 & $0.52-0.84$ & 0.70 & $0.49-1.00$ & 70 & 4.6 & 0.67 & $0.52-0.87$ & 0.67 & $0.47-1.00$ \\
\hline \multicolumn{13}{|l|}{ SGA } \\
\hline Control group & 252371 & 10.9 & 1.00 & ref & 1.00 & ref & 252371 & 10.9 & 1.00 & ref & 1.00 & ref \\
\hline Dental assistants & 994 & 10.6 & 0.97 & $0.90-1.05$ & 0.90 & $0.81-1.01$ & 400 & 10.7 & 0.99 & $0.87-1.11$ & 0.94 & $0.79-1.12$ \\
\hline Dentists & 193 & 9.3 & 0.84 & $0.72-0.99$ & 0.92 & $0.70-1.19$ & 130 & 8.3 & 0.74 & $0.61-0.90$ & 0.83 & $0.62-1.12$ \\
\hline \multicolumn{13}{|c|}{ Gender (proportion of boys) } \\
\hline Control group & 1192805 & 51.4 & 1.00 & ref & 1.00 & ref & 1192805 & 51.4 & 1.00 & ref & 1.00 & ref \\
\hline Dental assistants & 4776 & 51.0 & 0.98 & $0.94-1.02$ & 0.99 & $0.94-1.05$ & 1884 & 50.6 & 0.97 & $0.91-1.03$ & 0.96 & $0.88-1.05$ \\
\hline Dentists & 1076 & 52.0 & 1.02 & $0.94-1.12$ & 0.95 & $0.84-1.08$ & 822 & 52.3 & 1.04 & $0.94-1.15$ & 0.93 & $0.81-1.07$ \\
\hline \multicolumn{13}{|l|}{ Multiple births } \\
\hline Control group & 60169 & 2.6 & 1.00 & ref & 1.00 & ref & 60169 & 2.6 & 1.00 & ref & 1.00 & ref \\
\hline Dental assistants & 192 & 2.0 & 0.79 & $0.64-0.97$ & 0.80 & $0.60-1.06$ & 91 & 2.4 & 0.94 & $0.70-1.27$ & 0.66 & $0.42-1.04$ \\
\hline Dentists & 52 & 2.5 & 0.97 & $0.65-1.44$ & 1.04 & $0.64-1.71$ & 40 & 2.5 & 0.98 & $0.62-1.55$ & 1.00 & $0.57-1.73$ \\
\hline \multicolumn{13}{|l|}{ Stillbirth } \\
\hline Control group & 24888 & 1.1 & 1.00 & ref & 1.00 & ref & 24888 & 1.1 & 1.00 & ref & 1.00 & ref \\
\hline Dental assistants & 101 & 1.1 & 1.01 & $0.82-1.24$ & 1.16 & $0.88-1.53$ & 40 & 1.1 & 1.00 & $0.72-1.38$ & 1.04 & $0.69-1.57$ \\
\hline Dentists & 18 & 0.9 & 0.81 & $0.48-1.37$ & 1.04 & $0.53-2.05$ & 15 & 1.0 & 0.89 & $0.49-1.61$ & 1.11 & $0.54-2.28$ \\
\hline \multicolumn{13}{|l|}{ Prenatal death } \\
\hline Control group & 36832 & 1.6 & 1.00 & ref & 1.00 & ref & 36832 & 1.6 & 1.00 & ref & 1.00 & ref \\
\hline Dental assistants & 148 & 1.6 & 1.00 & $0.84-1.18$ & 1.06 & $0.83-1.34$ & 56 & 1.5 & 0.95 & $0.72-1.24$ & 0.95 & $0.66-1.35$ \\
\hline Dentists & 28 & 1.4 & 0.85 & $0.55-1.32$ & 1.13 & $0.66-1.93$ & 25 & 1.6 & 1.00 & $0.62-1.61$ & 1.26 & $0.73-2.20$ \\
\hline
\end{tabular}

${ }^{a}$ Known to have been employed as dental personnel prior to delivery.

${ }^{\mathrm{b}}$ Adjusted for maternal age, educational level and parity. Births clustered by mother.

be somewhat incomplete (22), mainly because many malformations are discovered some time after birth, this incomplete registration is not likely to be related to maternal occupation.

There were potential confounders for which we were unable to control, such as smoking during pregnancy, which is known to be related to low birth weight and preterm birth (23). Smoking habits are strongly correlated to education (24), but we cannot rule out the possibility of residual confounding.

Regrettably, our study is limited regarding exposure assessment. The main concern when this study was initiated was exposure to metallic mercury vapor, but with the available data it was not possible to estimate this exposure reliably. We do, however, have reason to assume that both dentists and dental assistants in Norwegian dental healthcare were exposed to metallic mercury to a varying degree at least until 1990 (17). Working as dental personnel in the period before delivery was used as an indicator of occupational exposure. This is clearly not specific for mercury and thus other occupational exposures in dental work are also included (eg, x-rays, chloroform, disinfectants, methyl methacrylate and organic solvents). Thus, this study cannot relate the occurrence of adverse pregnancy outcome to any specific substances, but rather assess whether the occupational exposure on a whole has had an effect. In addition, with such crude measurements of exposure, we can only make inferences on how employment as dental personnel might have affected reproductive outcomes on a group level, not among individuals.

Even with these uncertainties, mercury is our main concern regarding occupational exposure among dental personnel. Mercury vapor is easily absorbed when inhaled and is readily transported to other organs via the blood stream. In the organs, the metallic mercury is oxidized to form mercuric mercury, and this is thought to be the toxic species. Metallic mercury is mainly neurotoxic even though it is found in several organs, including the kidney, after exposure (25). Metallic mercury can also be transported across the placenta (26) and could thus affect the fetus. In the present study, the analyses stratified by time periods did not show any excess risk of congenital malformations or other adverse pregnancy outcomes among dental personnel, not even during the periods with frequent use of amalgam and especially copper amalgam (ie, 1967-1976 and 1977-1986). This indicates that the exposure to mercury vapor during these time periods did not 
cause any measurable excess risk of adverse pregnancy outcomes on a group level, among Norwegian dental personnel. Even so, we cannot exclude the possibility that there have been cases of mercury exposure high enough to cause reproductive effects among some individuals. In addition, as this study is based on data from MBRN, it does not address deliveries prior to 1967, a time period in which amalgam was in common use. Thus, any possible earlier effects, or effects among individuals, would not have been detected in this study.

Our results are in agreement with other registrybased studies. An earlier Norwegian study on neural tube defects in children of dental assistants did not find an increased risk for malformations (16) and a Swedish study did not find a higher-than-expected number of congenital malformations, prenatal deaths, or low birth weight among children of dental personnel (13). Our findings also correspond with two questionnaire-based studies; a British study on female dentists that did not find an increased occurrence of congenital malformations or low birth weight but an increased risk of miscarriages (8) and an American study on dental personnel that did not find an excess risk of congenital malformations or miscarriages (9). Regrettably, we did not have the opportunity to include miscarriages or infertility in our study, as these outcomes are not registered in the MBRN. A recent study on dental assistants from New Zealand showed a non-statistically significant increased risk of miscarriage, congenital malformations and low birth weight (7). An Italian study on lamp factory workers exposed to metallic mercury found an increased occurrence of congenital malformations, especially hip dysplasia, compared to the control group but no increase in miscarriages, prenatal mortality, or low birth weight (11). However, the authors suggested that the increased occurrence of hip dysplasia could be explained by regional differences in its prevalence in Italy. A small American study at a thermometer factory found a non-significant increase in the number of children with malformations in the exposed group, but no differences in the number of miscarriages (12).

Our study did not demonstrate any excess risks of the adverse pregnancy outcomes studied among dental personnel during 1967-2006. In fact, the majority of our risk estimates indicated a reduced occurrence among dental personnel, but, with a few exceptions in some of the stratified analyses, these were not statistically significant. We have, however, not adjusted the significance level owing to multiple testing and therefore the few significant estimates must be cautiously interpreted.

In conclusion, this study did not demonstrate any excess risks of congenital malformations or other selected adverse pregnancy outcomes among female dental personnel during 1967-2006. The results suggest that the previous occupational exposure to mercury in dentistry in Norway has not had a measurable deleteri- ous effect on pregnancy outcomes among dental personnel on a group level.

\section{Acknowledgements}

We thank the County Public Dental Services in all counties in Norway for help in identifying current and previous employees. We also thank the Norwegian Dental Association, Norwegian Dental Assistants Union, and Norwegian Union of Municipal and General Employees for providing information about their members. Patrica Flor is acknowledged for valuable linguistic help with the manuscript. This study was financed by the Norwegian Ministry of Labor and Inclusion.

\section{References}

1. Berlin M, Zalups RK, Fowler BA. Mercury. In: Nordberg GF, Fowler BA, Nordberg M, Friberg LT, editors. Handbook on the Toxicology of Metals. Third ed. Burlington: Academic Press; 2007. p675-729. doi:10.1016/B978-012369413-3/50088-4.

2. Aydin N, Karaoglanoglu S, Yigit A, Keles MS, Kirpinar I, Seven N. Neuropsychological effects of low mercury exposure in dental staff in Erzurum, Turkey. Int Dent J. 2003;53:85-91.

3. Langworth S, Sallsten G, Barregard L, Cynkier I, Lind ML, Soderman E. Exposure to mercury vapor and impact on health in the dental profession in Sweden. J Dent Res. 1997;76:1397404. doi:10.1177/00220345970760071001.

4. Moen B, Hollund B, Riise T. Neurological symptoms among dental assistants: a cross-sectional study. J Occup Med Toxicol. 2008;3:10. doi:10.1186/1745-6673-3-10.

5. Ritchie KA, Gilmour WH, Macdonald EB, Burke FJ, McGowan DA, Dale IM, et al. Health and neuropsychological functioning of dentists exposed to mercury. Occup Environ Med. 2002;59:287-93. doi:10.1136/oem.59.5.287.

6. Hilt B, Svendsen K, Syversen T, Aas O, Qvenild T, Sletvold $\mathrm{H}$, et al. Occurrence of cognitive symptoms in dental assistants with previous occupational exposure to metallic mercury. Neurotoxicology. 2009;30:1202-6. doi:10.1016/j. neuro.2009.04.012.

7. Jones L, Bunnell J, Stillman J. A 30-year follow-up of residual effects on New Zealand School Dental Nurses, from occupational mercury exposure. Hum Exp Toxicol. 2007;26:367-74. doi:10.1177/0960327107076824.

8. Nixon GS, Helsby CA, Gordon H, Hytten FE, Renson CE. Pregnancy outcome in female dentists. Br Dent J. 1979;146:39-42. doi:10.1038/sj.bdj.4804195.

9. Brodsky JB, Cohen EN, Whitcher C, Brown BW, Jr., Wu ML. Occupational exposure to mercury in dentistry and pregnancy outcome. J Am Dent Assoc. 1985;111:779-80.

10. Dahl JE, Sundby J, Hensten-Pettersen A, Jacobsen N. Dental 
workplace exposure and effect on fertility. Scand J Work Environ Health. 1999;25:285-90.

11. De Rosis F, Anastasio SP, Selvaggi L, Beltrame A, Moriani G. Female reproductive health in two lamp factories: effects of exposure to inorganic mercury vapour and stress factors. Br J Ind Med. 1985;42:488-94.

12. Elghany NA, Stopford W, Bunn WB, Fleming LE. Occupational exposure to inorganic mercury vapour and reproductive outcomes. Occup Med. 1997;47:333-6. doi:10.1093/occmed/47.6.333.

13. Ericson A, Kallen B. Pregnancy outcome in women working as dentists, dental assistants or dental technicians. Int Arch Occup Environ Health. 1989;61:329-33. doi:10.1007/BF00409388.

14. Heidam LZ. Spontaneous abortions among dental assistants, factory workers, painters, and gardening workers: a follow up study. J Epidemiol Community Health. 1984;38:149-55. doi:10.1136/jech.38.2.149.

15. Lindbohm ML, Ylostalo P, Sallmen M, Henriks-Eckerman ML, Nurminen T, Forss H, et al. Occupational exposure in dentistry and miscarriage. Occup Environ Med. 2007;64:12733. doi:10.1136/oem.2005.026039.

16. Irgens $\AA$, Krüger K, Skorve AH, Irgens LM. Har tannlegeassistenter økt risiko for å få barn med hjernemisdannelser? [Do dental assistants have an increased risk of having children with brain malformations?] Nor Tannlaegeforen Tid. 1997;107:856-8.

17. Svendsen K, Syversen T, Melo I, Hilt B. Historical exposure to mercury among Norwegian dental personnel. Scand J Work Environ Health. 2010;36:231-41.

18. Lenvik K, Woldbæk T, Halgard K. Kvikksølveksponering blant tannhelsepersonell [Exposure to mercury among dental personnel]. Nor Tannlaegeforen Tid. 2006;115:350-6.
19. Norseth J. Kvikksølveksposisjon på offentlige tannklinikker I Oslo - En yrkeshygienisk vurdering [Exposure to mercury in public dental clinics in Oslo--an occupational hazard evaluation]. Nor Tannlaegeforen Tid. 1977;87:371-6.

20. Irgens LM. The Medical Birth Registry of Norway. Epidemiological research and surveillance throughout 30 years. Acta Obstet Gynecol Scand. 2000;79:435-9. doi:10.1080/j.1600-0412.2000.079006435.x

21. Skjaerven R, Gjessing HK, Bakketeig LS. Birthweight by gestational age in Norway. Acta Obstet Gynecol Scand. 2000;79:440-9. doi:10.1080/j.1600-0412.2000.079006440.x

22. Kubon C, Sivertsen A, Vindenes HA, Abyholm F, Wilcox A, Lie RT. Completeness of registration of oral clefts in a medical birth registry: a population-based study. Acta Obstet Gynecol Scand. 2007;86:1453-7. doi:10.1080/08037050701645090

23. Murin S, Rafii R, Bilello K. Smoking and smoking cessation in pregnancy. Clin Chest Med. 2011;32:75-91, viii. doi:10.1016/j.ccm.2010.11.004

24. Schaap MM, Kunst AE. Monitoring of socio-economic inequalities in smoking: learning from the experiences of recent scientific studies. Public Health. 2009;123:103-9. doi:10.1016/j.puhe.2008.10.015

25. Clarkson TW, Magos L. The toxicology of mercury and its chemical compounds. Crit Rev Toxicol. 2006;36:609-62. doi:10.1080/10408440600845619

26. Wannag A, Skjaerasen J. Mercury accumulation in placenta and foetal membranes. A study of dental workers and their babies. Environ Physiol Biochem. 1975;5:348-52.

Received for publication: 12 March 2011 